\title{
Salvador das comerciantes: as mulheres na praça mercantil da Bahia (1872-1889)
}

\author{
Salvador of merchants: women in market square of Bahia \\ (1872-1889)
}

\section{Adriano Ferreira de Sousa*}

Resumo: Ao longo de praticamente todo o século XIX, o comércio formal em Salvador e nas principais praças mercantis do país era essencialmente masculino e majoritariamente composto por portugueses. Quer fossem patrões ou trabalhadores, os homens dominavam esse importante setor econômico. No entanto, em comparação com outras grandes cidades, tanto numericamente como proporcionalmente, a capital da Bahia contava com uma significativa presença de mulheres atuando no comércio. O presente artigo visa examinar essa presença feminina no comércio formal de Salvador entre 1872 e 1889. Ademais, salienta a importância das fontes provenientes da Junta Comercial do Estado da Bahia (JUCEB) para a pesquisa e análise histórica da sociedade baiana oitocentista. A despeito da preponderância masculina, o artigo revela que, apesar de raramente atuarem como trabalhadoras do comércio, algumas baianas tiveram fundamental importância como comerciantes e/ou fornecedoras de capitais necessários para a criação de lojas mercantis e das incipientes indústrias.

Palavras-chave: mulheres; comércio; Salvador.

Abstract: Throughout practically the entire nineteenth century, formal trade in Salvador and in the main commercial markets in the country was essentially male and mostly composed of Portuguese. Whether they were bosses or workers, men dominated this important economic sector. However, in comparison with other large cities, both numerically and proportionally, the capital of Bahia had a significant presence of women working in commerce. This article aims to examine this female presence in the formal trade of Salvador between 1872 and 1889. In

* Mestre em História Social pela Universidade Federal da Bahia (UFBA). Professor substituto do Departamento de História da UFBA. ORCID: https://orcid.org/0000-0002-4752-3701. E-mail: adriano25sousa@hotmail.com. 
addition, it stresses the importance of sources from the Junta Comercial do Estado da Bahia (JUCEB) for the research and historical analysis of 19th century Bahian society. Despite the male preponderance, the article reveals that, although they rarely act as commercial workers, some Bahians were of fundamental importance as employers and / or providers of capital necessary for the creation of mercantile stores and incipient industries.

Keywords: women; trade; Salvador.

TRADIçÃo MERCANTIL da cidade de Salvador remonta ao período colonial e se fortaleceu
ao longo do século XIX. Além da localização geográfica estratégica e do seu vasto porto, a criação em 1811 da Associação Comercial da Bahia (ACB), mais antiga entidade de classe do país e defensora por excelência dos interesses dos grandes comerciantes, ratifica a importância do comércio enquanto principal atividade econômica da cidade. No contexto oitocentista, a praça da Bahia (como era então conhecida), funcionava tanto como um grande centro importador e exportador de mercadorias para os mais diversos países, como também cumpria a função de redistribuir as mercadorias para as regiões mais longínquas da província e do país. Nesse sentido, a capital baiana era um grande centro de comércio internacional.

No entanto, o exercício das atividades comerciais não se restringia aos grandes comerciantes grossistas ligados à ACB e ao comércio internacional, mas congregava também um variadíssimo leque de trabalhadores ainda pouco conhecidos pela historiografia. Alguns labutavam individualmente e de maneira efêmera, como os vários vendedores ambulantes, mascates, caixeiros-viajantes e as caxinheiras, mulheres que mercadejavam pela cidade carregando caixas na cabeça. Outros ainda, em pequenos estabelecimentos fixos de comércio a retalho, atuavam em quitandas, vendas e barracas de secos e molhados, tavernas, casas de pasto etc.

Também existiam diversos lojistas de médio e grande porte que empregavam aprendizes e trabalhadores do comércio, que eram conhecidos como caixeiros - assim como os guardalivros, os caixeiros mais bem-sucedidos e que eram responsáveis pela contabilidade —, além de outros trabalhadores em seus estabelecimentos. Ainda havia quem alugasse seu próprio serviço, nesse caso, sua força física, como os trabalhadores dos cantos e os carregadores de cadeira de arruar. Em suma, como constatou a clássica tese da historiadora Kátia Mattoso, "vender era, de longe, o ofício mais praticado na Salvador do século XIX". ${ }^{1}$

Para além do tipo e do tamanho dos estabelecimentos, a histórica prática de mercadejar congregava sujeitos das mais variadas classes, raças, gêneros, condições jurídicas e nacionalidades. Todavia, cumpre ressaltar que, ao longo de quase todo o século XIX, o comércio formal na cidade - isto é, os estabelecimentos físicos e, por vezes, legalmente

1 MATTOSO, Kátia M. de Queirós. Bahia, século XIX: uma província no Império. Rio de Janeiro: Nova Fronteira, 1992. p. 490. 
registrados na Junta Comercial da Bahia (JUCEB), órgão responsável pelo registro das empresas e por cumprir outras funções administrativas - era predominantemente masculino e tinha forte presença de portugueses. ${ }^{2}$ Inclusive, essa predominância lusa em parte explica o antilusitanismo em Salvador e em outras grandes praças mercantis do país. ${ }^{3}$

Já no comércio informal oitocentista existia uma significativa presença de mulheres negras, como revela a pesquisa de Cecília Moreira Soares. ${ }^{4}$ As ganhadeiras, como eram chamadas, eram mulheres escravizadas, libertas ou livres que, em geral, comerciavam pelas ruas da cidade alimentos prontos, frutas, verduras, legumes, carnes e peixes. No que diz respeito às escravizadas, deveriam pagar uma quantia pré-fixada ao senhor, ficando o excedente sob sua posse. Após anos de trabalho e economia, esse pecúlio poderia servir - quem sabe - para comprar a liberdade, uma liberdade precária e nem sempre sólida e definitiva. ${ }^{5}$

Montando pequenas tendas em praças ou pontos de grande afluência de pessoas, carregando tabuleiros que poderiam ser fixos ou móveis, ou ainda equilibrando caixas, gamelas, cestos e trouxas sobre a cabeça, essas mulheres perambulavam pela cidade e ofereciam seus produtos de porta em porta. Conforme aponta a pesquisa de Richard Graham, entre fins do século XVIII e durante o século seguinte, essas vendedoras ambulantes em Salvador mantinham estreitos laços com pequenos lojistas, pescadores, açougueiros e barqueiros encarregados no transporte de alimentos. ${ }^{6}$ Essas mulheres eram, portanto, elos fundamentais numa emaranhada rede que ligava produtores e distribuidores até os consumidores finais.

A pesquisa de Graham também indica que, durante a primeira metade do século XIX, autoridades públicas, viajantes estrangeiros e demais contemporâneos, com certa frequência, reclamavam do transtorno público causado pelo grande número dessas mercadoras ambulantes. Essa situação não parece ter sofrido grandes mudanças mesmo no último quartel do século XIX. Segundo o periódico O Monitor, em fevereiro de 1878, o excesso de ganhadeiras nas ruas da cidade era tão grande que chegava a atrapalhar o livre trânsito e causava acidentes:

2 SANTOS, Mário Augusto da Silva. Comércio Português na Bahia (1870-1930). Salvador: Manoel Joaquim de Carvalho e Cia., 1978; GANDON, Tania Risério d'Almeida. Portugueses na Bahia na segunda metade do século XIX: emigração e comércio. $2^{\mathrm{a}}$ ed. Salvador: EDUNEB, 2010.

3 RIBEIRO, Gladys Sabina. Mata galegos: os portugueses e os conflitos de trabalho na República Velha. São Paulo: Brasiliense, 1990; MARTINHO, Lenira Menezes. Caixeiros e pés descalços: conflitos e tensões em um meio urbano em desenvolvimento. In: MARTINHO, Lenira Menezes; GORENSTEIN, Riva. Negociantes e caixeiros na sociedade da Independência. Coleção Biblioteca Carioca, v. 24. Rio de Janeiro: Secretaria Municipal de Cultura, Turismo e Esportes, Departamento Geral de Editoração, 1993; CÂMARA, Bruno Augusto Dornellas. Trabalho livre no Brasil imperial: o caso dos caixeiros de comércio na época da Insurreição Praieira. Dissertação (Mestrado em História) - Centro de Filosofia e Ciências Humanas, Universidade Federal de Pernambuco, Recife, 2005; SOUSA, Adriano Ferreira de. A laboriosa classe caixeiral: relações de trabalho e associativismo no comércio de Salvador (1875-1889). Dissertação (Mestrado em História) - Faculdade de Filosofia e Ciências Humanas, Universidade Federal da Bahia, Salvador, 2018.

4 SOARES, Cecília Conceição Moreira. Mulher negra na Bahia no século XIX. Salvador: EDUNEB, 2006.

5 CHALHOUB, Sidney. A força da escravidão: ilegalidade e costume no Brasil oitocentista. São Paulo: Companhia das Letras, 2012.

6 GRAHAM, Richard. Alimentar a cidade: das vendedoras de rua a reforma liberal (Salvador, 1780-1860). São Paulo: Companhia das Letras, 2013. 
chamamos a atenção da Câmara para o abuso que entre nós se pratica todas as horas e em quase toda a parte, de estarem os passeios das ruas tomadas por ganhadeiras e gamelas. Este abuso tem o inconveniente de obrigar os transeuntes a andar no meio das ruas, e é por isso que são tão frequentes os desastres nos lugares onde passam os bondes. ${ }^{7}$

A descrição do periódico à primeira vista pode parecer exagerada, no entanto, uma breve análise de outros jornais e fontes do período sugere que, de fato, Salvador contava com um comércio de rua extremamente perene e vivaz. Um texto publicado no mesmo periódico no mês seguinte também sugere outras motivações para o afastamento das ganhadeiras do comércio de rua. Segundo o "amigo dos melhoramentos", após a "empresa de quiosques e chalés" obter o direito legal de instalar "dez a doze galerias" na região portuária da Cidade Baixa, alguns comerciantes do local se mostraram insatisfeitos com a concessão da Câmara Municipal para a obra. ${ }^{8}$ Para o redator, a instalação de quiosques para o comércio de mercadorias também traria vantagens para os comerciantes já estabelecidos, uma vez que substituiria "o mercado sujo e repugnante das africanas" por "construções elegantes". Segundo dizia, era preciso "tirar o cais da África e pôr em seu lugar a Europa". Além dos interesses econômicos no empreendimento, o texto deixa claro o racismo e o desejo de "desafricanizar" a cidade, expulsando as ganhadeiras da região.

A significativa presença de negras e africanas empregadas no comércio de rua oitocentista não era exclusividade soteropolitana. Em Recife, como mostra Maciel Henrique Silva, vendedoras de rua e domésticas, escravizadas ou livres, teciam sua vida cotidiana sob um conjunto de representações senhoriais que Ihes exigia fidelidade, bom comportamento e honra. ${ }^{9}$ Entretanto, a despeito do que se dizia na imprensa e do comportamento esperado pelos empregadores, as experiências individuais discutidas pelo autor revelam situações bem complexas. Escravizadas e forras empregadas no comércio de rua se mostraram muito cientes da sua posição social e usaram de símbolos culturais dos grupos dominantes, a exemplo da honra, ainda que não necessariamente associada à sexualidade, como um dos argumentos fundamentais nas ações judiciais em que estavam envolvidas.

Por sua vez, na corte imperial, africanos ocidentais de ambos os sexos, homogeneizados como Minas, mantiveram forte presença no pequeno comércio de gêneros alimentícios dessa cidade..$^{10}$ Ao longo do século XIX, no mercado da Candelária e arredores, esses "pretos minas" reinventaram sua identidade social e se mantiveram como um grupo coeso por longo período. Parte deles, inclusive, antes de aportarem no Rio de Janeiro, viveram e trabalharam por longo período em Salvador e outras cidades baianas.

7 Fundação Biblioteca Nacional (daqui em diante FBN). O Monitor, Salvador, ed. 211, p. 1, 14 fev. 1878. Todos os jornais e periódicos listados foram consultados on-line no site da hemeroteca digital da Biblioteca Nacional. Disponível em: https://bndigital.bn.gov.br/hemeroteca-digital/. Acesso em: jun. 2020.

8 FBN. O Monitor, Salvador, ed. 228, p. 2, 6 mar. 1878.

9 SILVA, Maciel Henrique. Pretas de honra: vida e trabalho de domésticas e vendedoras no Recife do século XIX (1840-1870). Recife: Ed. Universitária da UFPE, coedição, Salvador: EDUFBA, 2011.

10 FARIAS, Juliana Barreto. Mercados Minas: africanos ocidentais na Praça do Mercado do Rio de Janeiro (18301890). $1^{\mathrm{a}}$ ed. Rio de Janeiro: Prefeitura do Rio de Janeiro/Arquivo Geral da Cidade, 2015. 
Conforme as pesquisas supracitadas mostram, a dinamicidade da economia de grandes praças mercantis como Salvador, Recife e na corte carioca possibilitou uma significativa presença e atuação das mulheres no comércio informal, sobretudo as africanas, mas também as crioulas cativas e forras e, em menor número, algumas brancas pobres. A despeito das variações de classe, raça, gênero, ofícios, nacionalidades e condições jurídicas, todas essas trabalhadoras partilhavam do comércio informal como principal meio de vida, trabalho e sociabilidade. Um universo que a história social do trabalho começa aos poucos a iluminar.

\section{O ingresso das mulheres no comércio formal}

É NOTÁVEL como a dimensão de classe é um elemento fundamental para compreender o exercício do comércio de rua pelas mulheres pobres. Independentemente de sua cor ou condição jurídica, a luta diária pela sobrevivência compelia essas mulheres ao trabalho. Diferente do que ocorria, por exemplo, com as mulheres das classes mais favorecidas que, conforme aponta Mattoso, geralmente não trabalhavam ou, quando muito, compartilhavam as responsabilidades com seus maridos no comércio formal. ${ }^{11} \mathrm{~A}$ mesma autora, possivelmente de maneira pioneira, aponta também que o ingresso dessas mulheres no comércio e nas atividades agrícolas geralmente se dava quando herdavam tais empreendimentos de seus maridos ou pais. Nesse sentido, tornar-se viúva e/ou não possuir filhos adultos, permitia, ou obrigava, o ingresso feminino no comércio. O mesmo tendia a ocorrer no caso das órfãs solteiras, sem irmãos adultos ou parentes do sexo masculino.

Essa constatação de Mattoso foi mais bem analisada pela dissertação de Silmária Souza Brandão que, com base em inventários, testamentos e almanaques, reconstruiu parte da trajetória de mulheres que atuaram no comércio e serviços em Salvador entre os anos de 1850 e 1888. ${ }^{12} \mathrm{~A}$ autora conseguiu catalogar aproximadamente 200 mulheres, a maioria viúvas ou órfãs, envolvidas no setor de comércio e serviços. No comércio, destacavam-se estabelecimentos diversos dirigidos por mulheres, como tavernas, hotéis, depósitos de cereais, lojas de ferragens, joias, miudezas, fazendas, calçados, entre outros. Segundo Brandão, a despeito da força do patriarcado e dos códigos morais e jurídicos da sociedade baiana do período, o ofício do comércio dava certa liberdade e autonomia a essas mulheres e muitas foram bem-sucedidas na administração dos negócios.

Já em sua tese, mediante uma articulada discussão em torno do gênero, dos micropoderes, da classe social, da etnia e da geração, a mesma autora foca o olhar nas viúvas comerciantes de Salvador entre 1850 e $1920 .{ }^{13}$ Segundo ela, longe de serem inválidas

11 MATTOSO, op. cit., p. 535.

12 BRANDÃO. Silmária Souza. No lar e no balcão: as mulheres na praça comercial de Salvador (1850-1888). Dissertação (Mestrado em Estudos Interdisciplinares sobre Mulheres, Gênero e Feminismo) - Núcleo de Estudos Interdisciplinares sobre Mulheres, Gênero e Feminismo, Universidade Federal da Bahia, Salvador, 2007.

13 BRANDÃO. Silmária Souza. Linhas partidas: viuvez, gênero e geração em Salvador (1850-1920). Tese (Doutorado em Estudos Interdisciplinares sobre Mulheres, Gênero e Feminismo) - Núcleo de Estudos 
ou economicamente improdutivas, muitas das viúvas comerciantes conseguiram administrar adequadamente os bens herdados e prosperar financeiramente. Ademais, cumpriram seu esperado papel social de mãe e zelaram pela união da família e educação dos filhos. Sob o olhar desconfiado dos juízes de família, do fisco e da sociedade, essas viúvas se reinventaram e se adaptaram a um mundo mercantil dominado pelos homens. A condição de viuvez as compeliu a se transformarem em autênticas chefes de família num contexto em que esse papel deveria, em tese, ser exclusivamente desempenhado pelos homens.

Apesar da relação de algumas viúvas com atividades financeiras e industriais, além de serem proprietárias de hotéis e pensões, Brandão aponta que em geral essas mulheres lidavam com o comércio de pequeno e médio porte, sobretudo no setor de moda, mediante a confecção e/ou venda de roupas prontas. $E$ ainda, não menos importante, na área de gêneros alimentícios sua presença em mercados e feiras era marcante.

Cumpre ressaltar de antemão, como ficará mais claro adiante, que as mulheres examinadas neste artigo não eram trabalhadoras do comércio propriamente ditas, isto é, não eram caixeiras; atuavam no comércio enquanto proprietárias e comerciantes. As fontes da JUCEB sugerem, inclusive, que boa parte sequer lidava diretamente com o público no comércio formal, mas serviam como prestadoras de capitais e sócias de firmas comerciais e de algumas indústrias. Eram mulheres que detinham consideráveis volumes de capitais e pertenciam às classes sociais mais abastadas e enriquecidas da cidade.

No Bahia e no Brasil oitocentista, o espaço público era, grosso modo, compreendido enquanto espaço masculino por excelência. A privacidade do lar, o cuidado da família e o exercício da maternidade eram reservados ao belo sexo. Assim sendo, práticas sociais e códigos morais de uma sociedade conservadora e patriarcal, em parte, explicam a pequena presença de mulheres no comércio formal e nas profissões liberais. No entanto, como já foi dito, a luta pela sobrevivência diária através do trabalho tornava esses códigos morais menos rígidos nas classes populares. Para além da moralidade, é preciso compreender que existiam empecilhos jurídicos para que as mulheres atuassem plenamente no comércio.

\section{As dificuldades jurídicas}

O CÓDIGO COMERCIAL, ordenamento jurídico que disciplinava todas as atividades mercantis no então Império brasileiro, foi criado através da Lei $n^{\circ} 556$, de 25 de junho de $1850 .{ }^{14}$ Segundo o art. $1^{\circ}$ desse código, todas as pessoas que possuíssem "livre administração de suas pessoas e bens, e não fossem expressamente proibidas" pela lei, poderiam comerciar. Logo, os escravizados, pessoas em tese despossuídos de personalidade jurídica, estavam

Interdisciplinares sobre Mulheres, Gênero e Feminismo, Universidade Federal da Bahia, Salvador, 2013.

14 BRASIL. Lei $n^{\circ}$ 556, de 25 de junho de 1850. Estatui o Código Comercial do Império do Brasil. Disponível em: https://www2.camara.leg.br/legin/fed/leimp/1824-1899/lei-556-25-junho-1850-501245-publicacaooriginal1-pl.html. Acesso em: 20 jun. 2020. 
legalmente excluídos do comércio. Todavia, as mulheres casadas e maiores de 18 anos deveriam ter "autorização de seus maridos para poderem comerciar em seu próprio nome", inclusive, a autorização deveria ser "provada por escritura pública". Caso a mulher estivesse "separada da coabitação dos maridos por sentença de divórcio perpétuo", a autorização não era necessária.

Embora não fosse expressamente declarado, o código comercial implicitamente considerava que qualquer mulher solteira e maior de 18 anos poderia comerciar. No entanto, o art. 29 da mesma lei deixava claro que, caso uma comerciante se casasse, o marido poderia proibir que a mesma continuasse no ofício. Isto é, a condição legal de casada poderia suprimir seu direito implícito (de solteira) ao pleno exercício do comércio. O citado artigo também destacava que, caso o marido não se opusesse, havia a presunção de que a comerciante estava autorizada a mercadejar. É notável, portanto, que a legislação conferia aos maridos um verdadeiro poder de tutela legal sobre suas esposas, inclusive, reafirmava essa tutela ao prever a possibilidade de revogação da autorização marital (art. 28).

Kátia Mattoso cita pelo menos dois casos em que os maridos concederam autorização para que suas mulheres pudessem comerciar. ${ }^{15}$ Mas, com base nos registros de matrículas de comerciantes provenientes do tribunal do comércio, órgão predecessor das juntas comerciais, foi possível identificar pelo menos mais dez autorizações similares concedidas entre 1857 e $1873 .{ }^{16}$ Como essa fonte específica é uma espécie de índice geral e não reproduz textualmente a autorização, além do nome e da nacionalidade, não foi possível obter maiores informações sobre os comerciantes e suas respectivas esposas. De todo modo, apresenta um claro indício de que a legislação tinha não só vigor como eficácia jurídica.

Além de tolher a participação feminina nas atividades típicas de compra e venda de mercadorias e serviços, a legislação reservava determinados ofícios exclusivamente para os homens. $\mathrm{O}$ art. 37, por exemplo, deixava claro que somente ao sexo masculino competia o exercício dos ofícios de corretor e de agente de leilões. Já em relação a outros ofícios auxiliares do comércio como feitores, guarda-livros, caixeiros, trapicheiros, administradores de armazéns de depósitos, entre outros, a lei era omissa e não fazia referência ao gênero.

É importante frisar que, para além do conservadorismo e das práticas sociais, não havia nenhuma explicação legal para as dificuldades criadas pela legislação para a efetiva participação feminina no comércio. Mais significativo ainda é o fato dessa discrepância de direitos só ter sido parcialmente corrigida no século seguinte, através do estatuto das mulheres casadas de 1962 que, dentre outros aspectos, retirou a mulher do grupo de pessoas tidas por juridicamente incapazes e deu maior autonomia para o exercício não só do comércio como de outros ofícios laborais. ${ }^{17}$

15 MATTOSO, op. cit., p. 665.

16 Arquivo Público do Estado da Bahia - Tribunal do Comércio - Registro de matrículas de comerciantes, corretores, agentes de leilões, trapicheiros e administradores de depósitos (1851-1896) - Livro 06 (59/08).

17 BRASIL. Lei n $^{\circ}$ 4.121, de 27 de agosto de 1962. Dispõe sobre a situação jurídica da mulher casada. Disponível em: http://www.planalto.gov.br/ccivil_03/leis/1950-1969//4121.htm. Acesso em: 10 jan. 2021. 
Reafirmando práticas sociais e códigos morais do contexto social em que foi produzido, o código comercial de 1850 restringia e criava empecilhos legais para a plena participação das mulheres no comércio. As mulheres figuravam nessa legislação como se fossem sujeitos de segunda categoria; de fato não Ihes era negado o direito de comerciar, no entanto, esse direito não era pleno, sobretudo se elas fossem casadas. Esses dados são importantes para a melhor compreensão da pequena presença das mulheres no comércio formal na Salvador oitocentista.

\section{As comerciantes no censo de 1872}

O CENSO DE 1872, apesar da imprecisão de alguns de seus dados, apresenta um retrato aproximado da realidade e serve como uma ferramenta fundamental para um exame quantitativo e panorâmico da sociedade brasileira de então. ${ }^{18}$ No que diz respeito aos ofícios mercantis, o censo não é claro e agrupa todas as pessoas ligadas ao comércio, independentemente de serem empregadores/patrões ou trabalhadores, numa ampla categoria genericamente descrita como "comerciantes, guarda-livros e caixeiros". A metodologia do censo não contabiliza a presença de escravizados no comércio, não esclarece se há distinção entre o comércio formal e informal e nem fornece detalhes acerca da cor/raça, classe. De todo modo, essas eventuais limitações de maneira alguma minimizam a importância analítica dessa fonte.

Antes de um exame mais profundo dos dados concernentes ao amplo grupo dos "comerciantes, guarda-livros e caixeiros", é interessante que se façam algumas ponderações hipotéticas acerca desse grupo impreciso. Os trabalhadores do comércio, sobretudo os caixeiros e aprendizes mais jovens e menos graduados, seguramente compreendiam a maior parte desse grupo, seguido por seus empregadores também do sexo masculino. As mulheres, por sua vez, possivelmente compreendiam ajuntamentos mais heterogêneos: as mais pobres concentravam-se no pequeno comércio informal de rua por conta própria; outras, pertencentes aos estratos sociais mais elevados, serviam quase que exclusivamente como prestadoras de capitais e sócias em lojas mercantis, manufaturas e fábricas; outras ainda, das classes sociais intermediárias, não só eram proprietárias como comerciantes propriamente ditas. Nesse sentido, parto do pressuposto de que todas as mulheres englobadas nessa categoria não eram trabalhadoras (caixeiras), mas atuavam e viviam, direta ou indiretamente, do comércio.

O histórico costume de empregar exclusivamente jovens do sexo masculino como aprendizes de caixeiros reforça a validade desse pressuposto. Os comerciantes portugueses, inclusive, encomendavam diretamente de Portugal crianças e adolescentes para os empregarem em suas lojas. Muitos desses jovens moravam com seus empregadores e viviam sob severas e aviltantes condições de trabalho e vida durante anos. Essa prática existia não só em Salvador como em todas as grandes praças mercantis do país. Além disso, ao longo

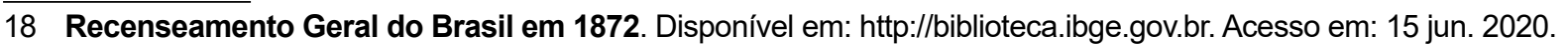


de todo o século XIX, e mesmo na primeira década do século seguinte, raros são os indícios nas fontes e na historiografia da presença de mulheres atuando como caixeiras, guarda-livros ou quaisquer outros dos ofícios auxiliares do comércio.

Examinando o associativismo laboral dos caixeiros e as relações e condições de trabalho dependente mantida entre patrões e trabalhadores do comércio entre 1875 e 1889, a dissertação de Adriano Ferreira de Sousa revela a quase inexistência de caixeiras na capital baiana. ${ }^{19}$ Já em relação à corte carioca, Fabiane Popinigis e Henrique Espada indicam que no século XIX o gênero, a raça e a classe desempenhavam papeis cruciais nos processos jurídicos envolvendo caixeiros e criadas. ${ }^{20}$ Mediante a comparação de processos movidos contra os patrões por falta de pagamento de salários, a pesquisa indica que, independentemente de serem criadas domésticas ou exercessem ao mesmo tempo a função de criada e caixeira, já que frequentemente a loja e a moradia praticamente ocupavam o mesmo espaço, o trabalho feminino era constantemente invisibilizado e associado à domesticidade pelos agentes da lei. Portanto, as aspirações femininas à cidadania e ao reconhecimento do seu trabalho esbaravam na ambiguidade jurídica - já que havia dificuldades em fixar exatamente qual o ordenamento normativo que fornecia base legal para as decisões dos casos - e na presunção do espaço público como espaço masculino por excelência.

Na virada do século, mais precisamente entre 1890 e 1911, a mesma autora ressalta em outra pesquisa a atipicidade do trabalho feminino nos estabelecimentos comerciais cariocas. ${ }^{21}$ No único caso encontrado e discutido por Popinigis, em que uma caixeira portuguesa foi agredida por seu amásio que era caixeiro e também português, os preconceitos de gênero foram os principais argumentos usados para absolver o réu e justificar a agressão física. Esse caso é emblemático ao mostrar as interações entre raça, classe e gênero nos mundos do trabalho. Embora a portuguesa fosse pobre, era uma mulher branca e supostamente mantida por seu amásio, que não via necessidade dela trabalhar e nem concordava com seu novo ofício de caixeira de casa de chope. Ser trabalhador do comércio, mesmo no começo do século XX, era uma profissão tida como "naturalmente" masculina. Por fim, a autora enfatiza que isso não era exclusividade do comércio; grosso modo, no contexto da Primeira República, as mulheres pobres que trabalhavam, por andarem em locais ditos "masculinos" ou em "horários impróprios", poderiam ser associadas à prostituição e serem tidas por desonestas. Apesar desses exemplos tirados das duas maiores praças mercantis não poderem ser indiscriminadamente estendido para todo o país, não é improvável que outras grandes capitais partilhassem dos mesmos aspectos.

19 SOUSA, op. cit., p. 42.

20 LIMA, Henrique Espada; POPINIGIS, Fabiane. Maids, Clerks, and the Shifting Landscape of Labor Relations in Rio de Janeiro, 1830s-1880s. International Review of Social History, volume 62, Special Issue S25, p. 45-73, dezembro 2017.

21 POPINIGIS, Fabiane. Proletários de casaca: trabalhadores do comércio carioca (1850-1911). Campinas: UNICAMP, 2007. p. 210-217. 
Voltando ao censo, como já foi dito acima, apesar de nenhum escravizado ter sido contabilizado na ampla categoria dos comerciantes, existem vários indícios do emprego de cativos no comércio e em algumas manufaturas e indústrias no século XIX. Registros de firmas da cidade de Salvador indicam que os escravizados não só faziam parte do capital de giro dos estabelecimentos, como também eram diretamente empregados no interior das lojas e trabalhavam juntamente com outros trabalhadores juridicamente livres. ${ }^{22}$ Situação análoga também ocorria na capital carioca ao longo dos oitocentos. ${ }^{23}$ É importante perceber que, ao suprimir os cativos do grupo dos comerciantes, o censo deve ter omitido parte significativa das escravizadas que atuavam no comércio informal, a exemplo das africanas ganhadeiras.

O censo indica que Salvador contava com 129.109 habitantes e era a segunda maior cidade do país em 1872. O Recife, com 116.671 habitantes, ficava na terceira posição. Por sua vez, o município neutro do Rio de Janeiro, corte e capital do Império, com seus 274.492 habitantes era a maior cidade do país. Juntas, essas três capitais eram as maiores praças mercantis do Brasil no período, cidades portuárias e fortemente inseridas no comércio internacional, uma análise comparativa do número de pessoas envolvidas no comércio nessas cidades traz importantes constatações.

O município neutro do Rio de Janeiro, apesar de ter 23.481 pessoas que viviam do comércio, contava com apenas 436 mulheres mercadoras. Ou seja, as mulheres eram menos de $2 \%$ do total de pessoas envolvidas no comércio. Já no Recife, havia 181 mulheres ligadas ao comércio que eram, percentualmente, menos de $5 \%$ do total das 3.820 pessoas que atuavam nesse setor. Por fim, a capital baiana, que tinha uma população empregada no comércio praticamente quatro vezes menor que a corte carioca, contava com pouco mais de $14 \%$ dessa população pertencente ao sexo feminino. Ou seja, 844 mulheres para um universo de 5.039 homens atuando no comércio, totalizando 5.883 pessoas.

Sintetizando, tanto numericamente como percentualmente, a presença feminina no comércio de Salvador era a maior dentre as três maiores capitais do país. Além disso, conforme indica a tabela abaixo, dentre as 20 capitais e a corte, apenas a cidade de Cuiabá tinha percentualmente mais mulheres no comércio do que a capital baiana. As 844 mulheres que atuavam no comércio soteropolitano representavam pouco mais de $36 \%$ de suas congêneres em todo o Brasil. Ainda não está claro o que explica essa significativa presença feminina no comércio de Salvador, mas é um dado extremamente relevante e que precisa ser mais bem esclarecido em pesquisas futuras mediante uma abordagem comparativa que leve em conta as especificidades de cada uma das capitais.

22 SOUSA, op. cit., p. 83-91.

23 MARTINHO, op. cit., p. 87-92. 
Tabela 1 - Quantidade e percentual de pessoas no comércio das capitais (1872)

\begin{tabular}{|c|c|c|c|c|c|c|}
\hline Província & Município & Homem & Mulher & $\begin{array}{l}\text { Percentual } \\
\text { de homens }\end{array}$ & $\begin{array}{c}\text { Percentual } \\
\text { de mulheres }\end{array}$ & $\begin{array}{c}\text { Número } \\
\text { total }\end{array}$ \\
\hline Alagoas & Maceió & 1.006 & 75 & $93,06 \%$ & $6,94 \%$ & 1.081 \\
\hline Amazonas & Manaus & 840 & 1 & $99,88 \%$ & $0,12 \%$ & 841 \\
\hline Bahia & Salvador & 5.039 & 844 & $85,65 \%$ & $14,35 \%$ & 5.883 \\
\hline Ceará & Fortaleza & 1098 & 68 & $94,17 \%$ & $5,83 \%$ & 1.166 \\
\hline Espírito Santo & Vitória & 235 & 35 & $87,04 \%$ & $12,96 \%$ & 270 \\
\hline Goiás & Goiás & 186 & 17 & $91,63 \%$ & $8,37 \%$ & 203 \\
\hline Maranhão & São Luís & 1.632 & 96 & $94,44 \%$ & $5,56 \%$ & 1.728 \\
\hline Mato Grosso & Cuiabá & 307 & 120 & $71,90 \%$ & $28,10 \%$ & 427 \\
\hline Minas Gerais & Ouro Preto & 539 & 9 & $98,36 \%$ & $1,64 \%$ & 548 \\
\hline Município neutro (Corte) & Rio de Janeiro & 23.241 & 387 & $98,36 \%$ & $1,64 \%$ & 23.628 \\
\hline Pará & Belém & 2.320 & 359 & $86,60 \%$ & $13,40 \%$ & 2.679 \\
\hline Paraíba & Paraíba & 246 & 11 & $95,72 \%$ & $4,28 \%$ & 257 \\
\hline Pernambuco & Recife & 3.639 & 181 & $95,26 \%$ & $4,74 \%$ & 3.820 \\
\hline Paraná & Curitiba & 270 & 9 & $96,77 \%$ & $3,23 \%$ & 279 \\
\hline Piauí & Teresina & 96 & 6 & $94,12 \%$ & $5,88 \%$ & 102 \\
\hline Rio de Janeiro & Niterói & 842 & 15 & $98,25 \%$ & $1,75 \%$ & 857 \\
\hline Rio Grande do Norte & Natal & 90 & 0 & $100,00 \%$ & $0,00 \%$ & 90 \\
\hline Rio Grande do Sul & Porto Alegre & 1.312 & 12 & $99,09 \%$ & $0,91 \%$ & 1.324 \\
\hline Santa Catarina & Desterro & 532 & 9 & $98,34 \%$ & $1,66 \%$ & 541 \\
\hline São Paulo & São Paulo & 580 & 66 & $89,78 \%$ & $10,22 \%$ & 646 \\
\hline Sergipe & Aracajú & 45 & 3 & $93,75 \%$ & $6,25 \%$ & 48 \\
\hline
\end{tabular}

Fonte: Censo de 1872, adapt.

Em 1872 Salvador contava com 18 freguesias, sendo 11 urbanas e oito rurais. Restringindo a análise para as freguesias urbanas, que eram as principais e que congregavam o grosso da população e do comércio, o número de pessoas atuando no comércio era de 5.490 , sendo as mulheres $13,22 \%$ desse total. O gráfico abaixo revela que as cinco freguesias urbanas que comportavam o maior número absoluto de moradores envolvidos no comércio eram, respectivamente, as freguesias de Santana (18,05\%), São Pedro Velho (17,34\%), Vitória $(17,14 \%)$, Conceição da Praia (12,55\%) e Santo Antônio Além do Carmo (9,40\%). Todavia, ao comparar esses números com o percentual da população total da freguesia, a Conceição da Praia ocupa lugar de destaque com $12,55 \%$ dos moradores envolvidos no comércio, seguida pelas freguesias do Passo $(8,77 \%)$, Vitória (8,07\%), São Pedro Velho $(6,46 \%)$ e Santana $(5,52 \%)$. 
Gráfico 1 - Número de pessoas no comércio das freguesias urbanas (1872)

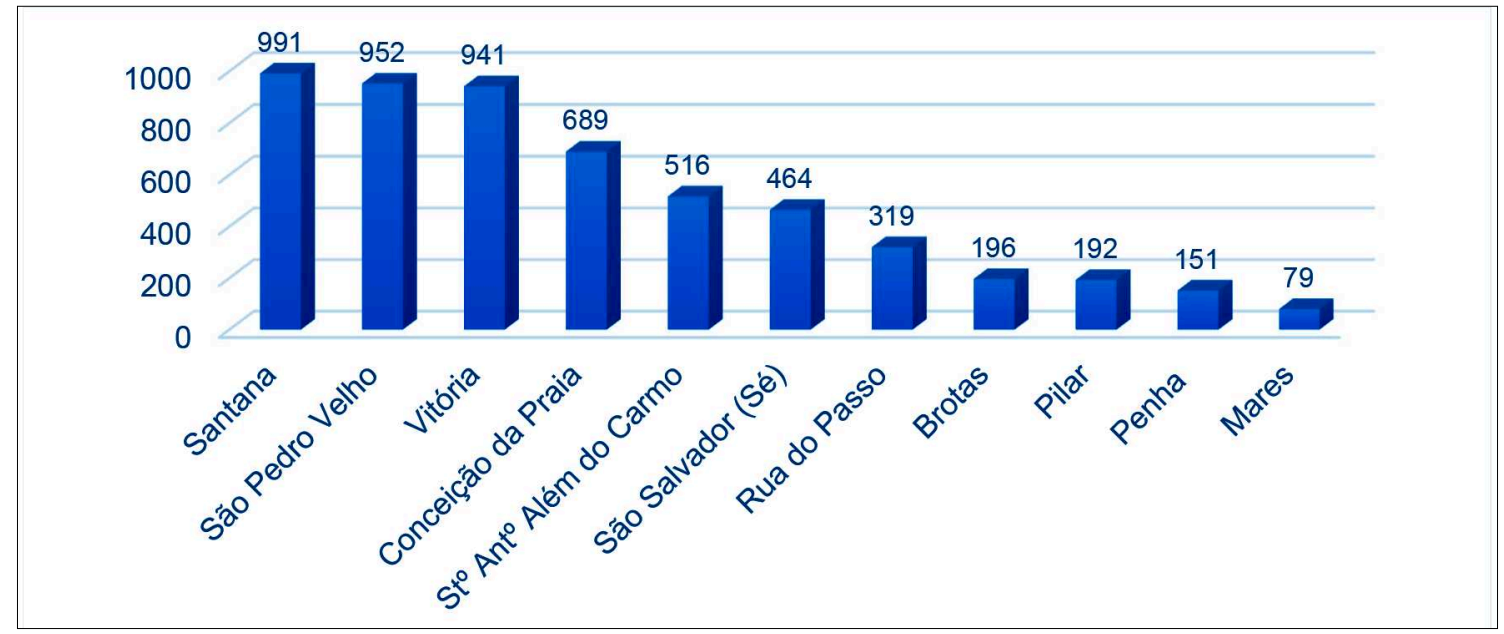

Fonte: Censo de 1872, adapt.

$\mathrm{Na}$ Cidade Baixa, as freguesias portuárias da Conceição da Praia e Pilar, tradicionais redutos do comércio da cidade, comportavam o equivalente a $16,04 \%$ de todo o comércio da cidade. Já na região da Cidade Alta, as maiores freguesias como Santana, Santo Antônio Além do Carmo, São Salvador, São Pedro Velho e Vitória, consequentemente, tinham os maiores números absolutos de pessoas envolvidas no comércio. Não é de se estranhar que a freguesia da Vitória, morada preferida de estrangeiros e prósperos comerciantes grossistas, fosse composta por elevado número de moradores dedicados à mercancia.

O próximo gráfico ilustra a divisão de gênero do trabalho no comércio em cada freguesia. Como já era de se esperar, a preponderância masculina é evidente, exceto na freguesia da Vitória, que se destaca não só por possuir mais mulheres que homens no comércio, como também por ser o local de morada de quase $70 \%$ (503) de todas as comerciantes da cidade. Outras freguesias com presença feminina no comércio eram a São Salvador (14,23\%), Pilar $(5,64 \%)$, Santana $(5,23 \%)$, Conceição da Praia $(3,44 \%)$ e Brotas $(2,06 \%)$.

\section{Gráfico 2 - Divisão de gênero no comércio das freguesias urbanas (1872)}

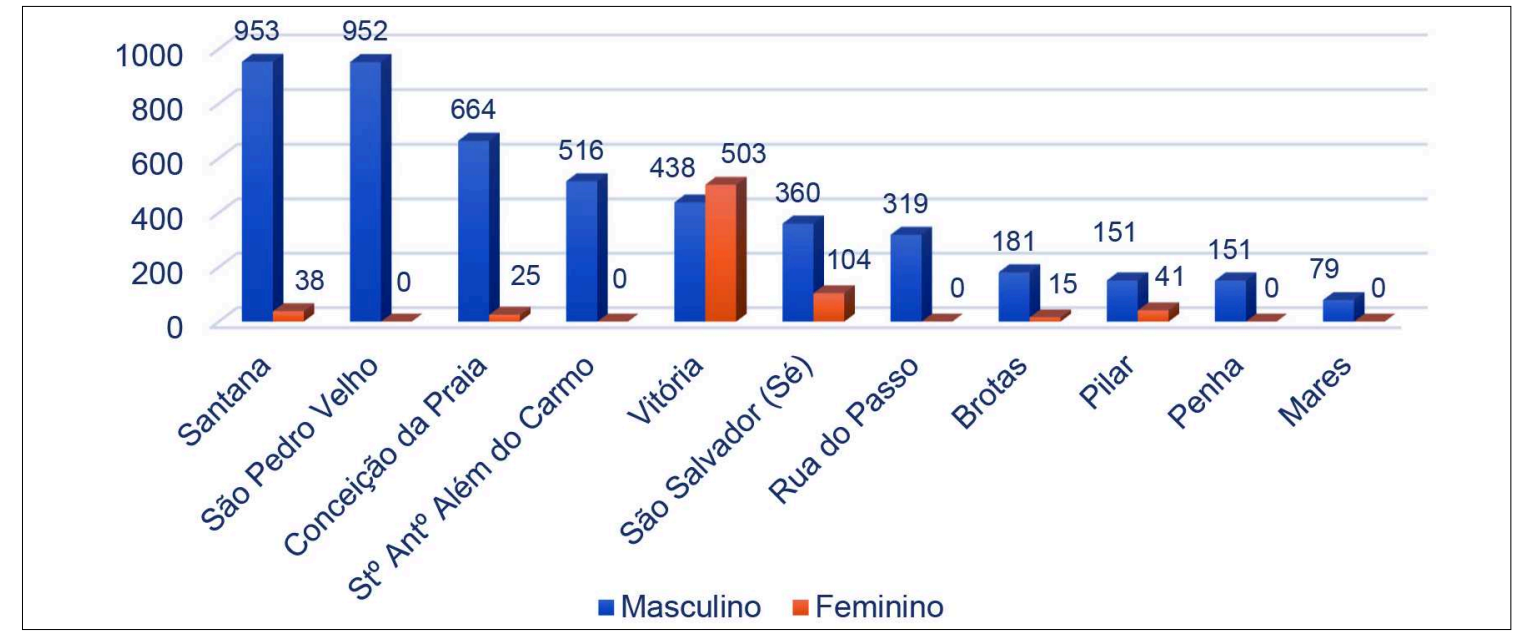

Fonte: Censo de 1872, adapt. 
Antes de refletir acerca dos motivos que explicam a elevada concentração das comerciantes na freguesia da Vitória, é importante fazer um cruzamento da relação entre o estado civil e a nacionalidade das mercadoras da cidade. O exame dessa relação possibilita extrair interessantes insinuações. Havia certo equilíbrio entre brasileiras e estrangeiras, sendo que as primeiras representavam cerca de $53 \%$ do comércio na cidade. Já em relação ao estado civil, brasileiras e estrangeiras solteiras somavam cerca de $53 \%$ do contingente mercantil da cidade, enquanto as casadas eram cerca de $32 \%$, e, por fim, as viúvas representavam pouco mais de $14 \%$. Independentemente da nacionalidade, o índice percentual das viúvas comerciantes tendia a se aproximar, sendo as brasileiras cerca de $13 \%$ e as estrangeiras pouco mais de $15 \%$. Em todo caso, as viúvas eram minoria. Dentre as casadas, cerca de $45 \%$ eram brasileiras enquanto as estrangeiras somavam apenas $17 \%$. Por fim, a maioria das comerciantes estrangeiras era solteira (67\%) enquanto as brasileiras representavam cerca de $41 \%$.

No que diz respeito às brasileiras, o estado civil não parecia determinar necessariamente uma maior ou menor presença no comércio já que, como visto acima, o nível percentual de casadas e solteiras que mercadejavam era relativamente próximo. Por sua vez, a discrepância entre o número de estrangeiras casadas e solteiras que atuavam no comércio parece insinuar que, nesse círculo específico, o estado civil de casada poderia limitar a autonomia dessas mulheres.

Embora não tenha sido possível identificar no censo dados referentes à renda/classe dessas comerciantes, o fato da maioria delas se concentrarem na freguesia da Vitória indica que, seguramente, pertenciam às classes sociais mais elevadas. Inclusive, esse dado é interessante pois é mais um indício de que a metodologia do censo, pelo menos em relação às mulheres, se restringe ao comércio formal. Ou ainda, mais um reflexo da completa inexistência de caixeiras na cidade. A Vitória era uma freguesia burguesa, elitista e morada predileta de estrangeiros e brasileiros abastados. ${ }^{24}$ Não é improvável que a maioria dessas mercadoras mapeadas pelo censo fosse afortunada e servisse como prestadora de capitais para firmas comerciais, indústrias manufatureiras ou outras atividades financeiras similares. Não lidavam diretamente com os clientes no balcão, mas se associavam a empreendimentos mercantis e financeiros lucrativos e viviam das rendas daí auferidas.

\section{As comerciantes nas fontes da Junta Comercial da Bahia}

AS JUNTAS COMERCIAIS foram órgãos administrativos criados em algumas capitais do país pelo Decreto $n^{0} 6.384$, de $1876 .{ }^{25}$ Elas substituíam os três tribunais do comércio que existiam em Salvador, Recife e na corte carioca desde 1850. Na prática, eram responsáveis pelo registro

24 NASCIMENTO, Anna Amélia Vieira. Dez freguesias da cidade do Salvador: aspectos sociais e urbanos do século XIX. Salvador: Fundação Cultural do Estado da Bahia, 1986.

25 BRASIL. Decreto $n^{\circ}$ 6.384, de 30 de novembro de 1876. Organiza as Juntas e Inspetorias Comerciais e regula o exercício das respectivas funções. Disponível em: https://www2.camara.leg.br/legin/fed/decret/1824-1899/ decreto-6384-30-novembro-1876-549726-publicacaooriginal-65239-pe.html. Acesso em: 18 jun. 2020. 
de empresas, comerciantes, caixeiros e outros ofícios ligados ao comércio. Para além dessas funções administrativas, também era o órgão competente para julgar causas comerciais em primeira instância. A criação dessas juntas foi um reflexo direto do crescimento urbano e da ampliação significativa das trocas mercantis no país.

Tanto os tribunais como as juntas deixaram amplos e diversificados acervos documentais. A julgar pelo peso do comércio baiano, trata-se de um volume documental gigantesco e extremamente relevante para a pesquisa da história econômica e social da Bahia e do Brasil ao longo dos séculos XIX e XX. Uma parte dessa documentação encontra-se sob a guarda do Arquivo Público do Estado da Bahia (APEB) e está disponível ao público, a exemplo dos livros de registro de matrícula de comerciantes. Outra parte, até recentemente, encontrava-se sob a guarda do mesmo arquivo mas estava inacessível e sequer tinha sido higienizada e catalogada. ${ }^{26}$

Consegui acessar parte das fontes indisponíveis para consulta e que estavam sob a guarda do APEB, que são 13 livros de contratos e distratos mercantis, além de outros documentos similares pertinentes a alterações nos contratos das firmas. Essas fontes oferecem informações detalhadas sobre a criação e o funcionamento dos estabelecimentos. Os contratos mercantis, por exemplo, descrevem o nome, a nacionalidade, os tipos de sócios e suas respectivas responsabilidades legais, a quantidade de capitais investidos, os ramos de atuação, o tipo de mercadoria comercializada, o tempo de duração da sociedade, a remuneração dos sócios etc. Os distratos mercantis, por sua vez, trazem esclarecimentos acerca da dissolução dos contratos. Só para ter uma ideia, apenas com esses 13 volumes foi possível identificar 842 documentos que compreendem cerca de sete mil páginas e abarcam os anos de 1875 e 1889. ${ }^{27}$ Cumpre ressaltar que os livros de contratos e distratos são apenas parte desse fundo documental, o acervo é muito maior e somam pelo menos 185 volumes diversos de registros empresariais dos séculos XIX e XX.

Como já era esperado, a maior parte dos contratos e distratos que tive acesso se referia a homens, mas foram identificados 69 documentos nos quais 61 mulheres são diretamente citadas. Exclusivamente em Salvador, 51 mulheres são citadas nessas fontes, sendo que pelo menos em dois terços desse grupo foi possível identificar com segurança que se tratava de viúvas, órfãs, ou mães de homens associados às firmas. No entanto, nem todas eram necessariamente comerciantes. Em dezembro de 1877, por exemplo, Rita Augusta de Figueiredo Lopes, viúva do brasileiro José Paulo Lopes, figurou no documento de dissolução parcial da sociedade mercantil e recebeu os rendimentos de seu marido. ${ }^{28} \mathrm{O}$ falecido era sócio de indústria, isto é, não forneceu capital para a sociedade, mas ingressou com seu tempo e mão de obra na loja de miudezas de Soares Cunha e Cia. Além disso, era responsável pela escrituração mercantil, sendo, portanto, sócio e guarda-livros.

26 Em outubro de 2015, um convênio ( $n^{\circ}$ 20/2015) foi firmado entre a Fundação Pedro Calmon e a Junta Comercial do Estado da Bahia (JUCEB) para preservação de 185 volumes do acervo da JUCEB. Em junho de 2017, por falta de verbas, o convênio foi rescindido e foi determinado que o acervo documental retornasse à JUCEB.

27 Nesse intervalo de tempo apenas o livro referente ao ano de 1887 não foi encontrado.

28 Junta Comercial do Estado da Bahia (doravante JUCEB). Contratos, alterações e distratos, n. 137, 1877. 
Foram identificados mais 13 casos similares ao de Rita que, por não servirem aos propósitos do artigo, foram descartados do exame a seguir. Nos 37 casos restantes, identifiquei 17 viúvas, uma órfã de pai, uma mãe que herdou bens do filho e uma herdeira indeterminada, totalizando 20 mulheres que já comerciavam ou decidiram comerciar com os bens herdados. Em acréscimo, não foi possível determinar o estado civil das 17 comerciantes restantes. De todo modo, ratificando indícios já apontados ao longo do texto, é notável o fato de pouco mais da metade das comerciantes citadas nos contratos e distratos da JUCEB serem viúvas ou herdeiras de bens.

Apesar de atuarem em diversos ramos do comércio e mesmo nas incipientes fábricas e manufaturas, conforme indica a tabela seguinte, a maior parte dessas mulheres estava associada a escritórios e lojas de fazendas, fábricas, uma empresa de pesca e um teatro. Fazenda era um termo genérico que se referia a diversas mercadorias: gêneros alimentícios, tecidos, bebidas etc. As seis fábricas que contavam com mulheres dentre os associados produziam sabão, azeite de mamona, fósforos, tecidos, fumo, cigarros e derivados. Por fim, também existiam mulheres associadas a diversas lojas, um restaurante, um hotel, uma empresa de transporte marítimo e uma oficina de tinturaria.

Tabela 2 - Ramos de atuação das comerciantes (1875-1889)

\begin{tabular}{|l|c|}
\hline Tipo de estabelecimento & $\begin{array}{c}\text { Número de mulheres } \\
\text { associadas }\end{array}$ \\
\hline Escritórios e lojas de fazendas & 10 \\
\hline Fábricas & 8 \\
\hline Empresa de pesca & 6 \\
\hline Teatro & 3 \\
\hline Miudezas e quinquilharias & 2 \\
\hline Relojoaria/joalheria & 2 \\
\hline Loja de comissões & 2 \\
\hline Indefinido & 1 \\
\hline Transporte marítimo & 1 \\
\hline Restaurante & 1 \\
\hline Loja de moda & 1 \\
\hline Hotel & 1 \\
\hline Cutilaria & 1 \\
\hline Oficina de tinturaria & 1 \\
\hline Gêneros de estiva & 1 \\
\hline
\end{tabular}

Fonte: JUCEB, registros de contratos, alterações e distratos (1875-1889).

Conforme a já citada pesquisa de Brandão demonstrou, o setor de moda e o pequeno comércio varejista de alimentos tinha importante participação feminina em Salvador. Mas, para a infelicidade dos historiadores, raramente as firmas de pequeno porte eram registradas na JUCEB. O volume de capitais investidos por essas mulheres é um claro indicativo do 
pertencimento social delas. Quantias menores que 500 mil réis foram minorias e representam as ações compradas na empresa de pesca da firma de Bartolomeu da Costa e Cia., uma sociedade em comandita criada em julho de 1883, e no Teatro Politeama Baiano, uma sociedade anônima fundada em dezembro de $1885 .{ }^{29}$

A maioria das firmas foram criadas com capitais que variavam entre 12 a 79 contos de réis, fortunas que, com base na classificação de Kátia Mattoso, poderiam ser definidas entre o grupo das médias altas e grandes baixas. ${ }^{30} \mathrm{~A}$ brasileira e viúva Cândida Maria Ferreira de Oliveira, por exemplo, usou pouco mais de 66 contos de réis, sua parte da herança de seu finado marido, para continuar os negócios num escritório de fazendas por atacado e a retalho. ${ }^{31} \mathrm{~A}$ nova firma, uma sociedade mercantil solidária, foi fundada em janeiro de 1881 com sua filha, seu filho e seu genro e tinha um capital social de pouco mais de 172 contos de réis. Em suma, os registros da JUCEB ratificam a forte presença de mulheres abastadas no comércio formal da cidade.

A francesa Maria Felicidade Boucher, viúva do também francês José Boucher, decidiu continuar com o estabelecimento após a morte do marido em junho de 1877.32 Quatro meses depois, fez um contrato de sociedade solidária com seu filho para que ambos administrassem a oficina de tinturaria herdada do marido, que existia pelo menos desde o ano de $1857 .{ }^{33}$ Segundo o contrato, o capital social era de pouco mais de 15 contos de réis em máquinas, móveis e outros utensílios que era a herança de ambos. Cada sócio receberia mensalmente a quantia de 100 mil réis para suas despesas e os lucros seriam repartidos igualmente a cada seis meses. O filho seria o responsável pela administração da oficina e por lidar diretamente com os trabalhadores como julgasse conveniente. À viúva Boucher, por sua vez, caberia exclusivamente a "administração financeira da casa", as "despesas gerais" e a "arrecadação da receita".

Além de sócia, a viúva certamente tinha conhecimentos específicos de escrituração mercantil, já que atuava como guarda-livros da firma. Talvez essa experiência tenha sido adquirida ao longo das três décadas auxiliando o falecido marido no empreendimento. Como já foi definido, era raro que as mulheres atuassem diretamente no comércio, essa fonte, no entanto, evidencia o tino comercial da viúva. Ao lidar diretamente com fornecedores, clientes, credores e com todas as finanças do empreendimento, a viúva demonstrava, a despeito do seu esperado papel social, que conhecia muito bem aquele ambiente. Será que o fato de não ser brasileira propiciou seu desembaraço no ofício? Por ora é impossível saber. Dois anos depois, conforme previa o contrato, o distrato (dissolução do contrato) foi feito e a viúva saiu da sociedade recebendo oito contos de réis do filho. Não é improvável que, na prática, a senhora Boucher tenha auxiliado seu filho nos meandros da administração

29 JUCEB. Contratos... n. 561, 1883; n. 671, 1885.

30 MATTOSO, op. cit., p. 608.

31 JUCEB. Contratos... n. 385, 1881.

32 JUCEB. Contratos... n. 130, 1877.

33 FBM. Almanak Administrativo, Mercantil e Industrial da Bahia. $3^{a}$ ed. Salvador. p. 383. 
financeira da firma durante o tempo do contrato. Inclusive, a firma continuou a funcionar apenas com o filho.

Diferentemente da francesa, a brasileira Hortência Clara do Espírito Santo forneceu em maio de 1876 todo o capital de oito contos de réis para a criação de uma loja de modas nacionais e estrangeiras com o sócio português Manoel Zaluzard Schiappe. ${ }^{34}$ Além disso, o sócio deveria administrar e manter toda a organização financeira da loja, devendo, sempre que fosse solicitado, fornecer os livros contábeis para que a sócia capitalista pudesse examiná-los. Os lucros seriam anualmente creditados em partes iguais para cada sócio e ambos receberiam mensalmente a quantia de 150 mil réis. De maneira parecida fez a portuguesa Maria Emília da Costa que, apesar de ser sócia comanditária e fornecer a significativa quantia de 60 contos de réis para a firma Moraes e Cia., não administrava diretamente o empreendimento e sequer morava na capital onde a empresa estava estabelecida. ${ }^{35} \mathrm{~A}$ gerência cabia a dois sócios comanditados que também eram portugueses. A firma, com o significativo capital social de 220 contos de réis, foi criada em março de 1882 e deveria mercadejar "fazendas ou quaisquer outras mercadorias nacionais e estrangeiras". Em fevereiro de 1888, o distrato dessa firma deixa claro que o empreendimento foi muito bem-sucedido já que, ao se retirar da sociedade, a sócia Maria Emília da Costa recebeu a elevada quantia de pouco mais de 109 contos de réis. ${ }^{36}$

O caso da viúva brasileira Olympia Cândida Mendes Pontes também ilustra não só o considerável volume de capital investido como o retorno financeiro auferido. Em dezembro de 1877, o comerciante português Antônio Martins Leite renovou na JUCEB um contrato de firma social que ele tinha com essa viúva desde 1874. Segundo informa, a firma Viúva Pontes e Leite continuaria com o negócio de "compra e venda de fazendas, descontos e quaisquer outras transações" lícitas com pouco mais de 61 contos de réis de capital social. ${ }^{37} \mathrm{~A}$ viúva forneceria cerca de 47 contos de réis e o sócio português pouco mais de 13 contos de réis. Antônio Leite era o caixa e sócio responsável pela administração do estabelecimento, os lucros e prejuízos seriam igualmente divididos. Em março de 1882, o distrato da firma foi realizado e o sócio português foi indenizado e se retirou da sociedade, que continuou apenas com a viúva, que ficou com todo o capital social avaliado em pouco mais de 86 contos de réis. ${ }^{38}$

Dois meses depois, em julho de 1882, a viúva Pontes criou uma nova firma com o sócio português Leonardo Henrique de Azevedo intitulada Viúva Pontes e Azevedo. ${ }^{39}$ A nova firma lidava com o ramo de compra e venda de fazendas, gêneros por consignação e descontos de letras. O capital social era de 35 contos de réis, sendo que 27 contos de réis foi fornecido pela viúva. Tal qual a firma anterior, coube ao sócio Leonardo Azevedo a gerência e administração

\footnotetext{
34 JUCEB. Contratos... n. 41, 1877.

35 JUCEB. Contratos... n. 421, 1882.

36 JUCEB. Contratos... n. 829, 1888.

37 JUCEB. Contratos... n. 154, 1878.

38 JUCEB. Contratos... n. 415, 1882.

39 JUCEB. Contratos... n. 451, 1882.
} 
do estabelecimento e os lucros e perdas seriam igualmente repartidos. No distrato dessa nova firma, feito em dezembro de 1884, a viúva novamente assumiu todo o ativo e passivo da firma, avaliado em pouco mais de 53 contos de réis, e isentou o ex-sócio de quaisquer responsabilidades legais. ${ }^{40}$ Mesmo considerando eventuais dívidas ativas e responsabilidades com credores dessas firmas, chama a atenção o grande volume de capitais que a viúva Pontes tinha ao seu dispor e administrava, bem como seus possíveis contatos com outros comerciantes, sócios e credores. Infelizmente não foi possível identificar qual o destino dos capitais auferidos nessa última firma.

Condizente com as práticas sociais costumeiras vigentes no período, os três últimos exemplos acima citados são os mais comuns entre as fontes da JUCEB. Quase todas as mulheres figuravam apenas como credoras e sócias dos estabelecimentos. Muitas vezes elas forneciam todo o capital social necessário ou uma parte significativa do mesmo. A gerência e a administração financeira, assim como o trato com os funcionários e caixeiros dos negócios, cabia quase sempre aos associados do sexo masculino, muito dos quais seus filhos e pais. Sendo bem provável que muitas dessas mulheres sequer visitassem essas firmas com frequência.

Diferentemente de todos os contratos até aqui examinados, a firma de Rocha e Cia. se destacava por ser uma empresa composta exclusivamente por duas mulheres. Segundo o contrato, as brasileiras Amélia Augusta da Costa Rocha e Paulina Silveira da Costa Rocha, possíveis parentes a julgar pelo nome, criaram a firma em julho de 1876 com o objetivo de fabricar e "vender óleo de mamona purificado numa fábrica a vapor". ${ }^{41}$ Ambas moravam na freguesia dos Mares e a fábrica, como muitas outras no período, foi estabelecida na região da "Calçada do Bomfim". O capital social investido era de nove contos de réis, sendo que Amélia forneceria todo o maquinário e uma parte em dinheiro, totalizando seis contos e 800 mil réis. O restante do capital foi disponibilizado em espécie pela sócia Paulina.

Toda a gerência do estabelecimento era responsabilidade de Paulina, que deveria zelar para que "a gente empregada no serviço da fábrica trabalhe com vontade, não perca tempo" e evite "qualquer prejuízo feito por trabalho mal feito". Também era sua função fazer os pagamentos semanais dos funcionários. Por fim, Paulina também manteria todos os livros contábeis devidamente atualizados e forneceria balanços mercantis a cada seis meses. Os lucros e prejuízos seriam igualmente repartidos e as duas poderiam retirar 400 mil réis anuais para suas despesas.

É interessante a ênfase dada pelo contrato da necessidade de uma gerência racional e eficiente dos recursos e do tempo dos trabalhadores. Além disso, Paulina de fato concentrava os poderes de gerente administrativa e financeira da fábrica. Atuando tanto como uma espécie de capataz da firma ao fiscalizar o trabalho e realizar os pagamentos devidos aos funcionários,

40 JUCEB. Contratos... n. 604, 1884.

41 JUCEB. Contratos... n. 51, 1876. 
como também era a gerente contábil e a guarda-livros propriamente dita do estabelecimento. Em acréscimo, cumpre salientar que a firma contava com pelo menos um caixeiro que era subordinado à gerente. Contrariando práticas sociais comuns na sociedade baiana oitocentista, Paulina percorria ambientes socialmente reservados ao sexo masculino. Possivelmente lidava com fornecedores de mamona no porto da cidade e organizava o transporte da matéria-prima até a fábrica, talvez até com alguns dos trabalhadores de canto da região. Ainda examinava o trabalho realizado pelos funcionários da fábrica e a qualidade do óleo produzido que seria, finalmente, comerciado com os revendedores. O azeite produzido deveria ser repassado para boticários e farmacêuticos, já que na época era muito usado para fins medicinais.

Apesar de não ter sido possível identificar o grau de parentesco das sócias, a fábrica parecia ter sido, pelo menos até o ano de 1874, propriedade de Antônio Moreira da Rocha, outro possível parente conforme sugere o último sobrenome. ${ }^{42}$ Não sendo improvável, inclusive, que fosse o pai de ambas ou de uma das sócias. Apesar da previsão contratual de que a sociedade deveria funcionar durante três anos, infelizmente não foi encontrado qualquer outro documento acerca do que ocorreu com a firma.

O fato de a maioria das mulheres não atuarem diretamente nos estabelecimentos, como fizeram a francesa Maria Boucher e a brasileira Paulina Rocha, não significava necessariamente que lhes faltasse interesse ou tino comercial. Talvez fosse mais cômodo atuar de longe como acionista de diferentes firmas, e assim fez Antônia Amélia Moreira ao investir um pouco mais de um conto de réis tanto numa fábrica de rapé, cigarros e sabão como numa empresa pesqueira no ano de $1883 . .^{43} \mathrm{Ou}$, ainda, a viúva brasileira Leopoldina Kelsch Ballalai que, após a morte do marido, delegou a administração de dois empreendimentos herdados ao seu sócio, o brasileiro Antônio Luiz Alves Júnior. O contrato firmado no final de 1883, e que era referente ao Hotel Paris, estabelecimento situado ao lado da ladeira do mosteiro de São Bento (Cidade Alta), tornava Antônio o gerente e responsável. ${ }^{44}$ No ano seguinte um novo acordo definia que o mesmo sócio também deveria cuidar do restaurante La belle jardinière, esse último localizado na Cidade Baixa, à rua das Princesas. ${ }^{45}$

Um aspecto importante que essas fontes sugerem é a frequência dos laços familiares nos contratos e, mais interessante ainda, o significativo auxílio muitas vezes prestado por essas mulheres ao disponibilizar o capital social necessário para a criação das firmas. Além dos exemplos supracitados, essa tendência é explicitamente expressa num contrato feito em março de 1885 entre a viúva Margarida Barbette Aschlimann e o suíço Georges Aschlimann. ${ }^{46}$ Como sócia comanditária, a viúva forneceu o capital de 19 contos de réis em dívidas, dinheiro e mercadorias. O sócio responsável, por seu turno, ofereceu dois contos de réis em dinheiro. A administração da loja competia exclusivamente ao sócio responsável. Lucros e perdas seriam

42 FBN. Relatório dos Trabalhos do Conselho Interino de Governo. $1^{\text {a }}$ ed. Salvador, 1874. p. 253.

43 JUCEB. Contratos... n. 516 e n. 581, 1883.

44 JUCEB. Contratos... n. 541, 1883.

45 JUCEB. Contratos... n. 550, 1884.

46 JUCEB. Contratos... n. 626, 1885. 
divididos na proporção de $60 \%$ para a viúva e $40 \%$ para Georges; a primeira receberia 300 mil réis mensais e o último 200 mil réis, sendo que a firma deveria durar pelo tempo de cinco anos.

Embora a fonte não deixe claro, possivelmente o sócio era cunhado da viúva e irmão do seu falecido marido. Elemento relevante é a previsão legal de que Georges se comprometia a devolver todo o capital investido pela viúva. Assim sendo, a cada seis meses ele estava obrigado a fornecer a Margarida dez letras mercantis, que era uma espécie de título de crédito, durante os cinco anos de duração da firma. Ou seja, na prática, o capital de giro da loja nada mais era que um empréstimo fornecido pela viúva. Após o pagamento da dívida, a firma passaria a ser exclusivamente do sócio e Margarida se isentaria de todas as responsabilidades legais com os credores e devedores. Georges de fato pagou a dívida e se tornou dono e único responsável pela loja, como revela o distrato da firma registrado um ano depois, em março de 1886. ${ }^{47}$ Segundo esse documento, como a viúva ainda era dona de quase 12 contos de réis, o sócio responsável lhe pagou uma parte em dinheiro e dividiu os dez contos de réis restantes em letras mercantis que seriam creditadas ao longo dos 13 meses seguintes.

$\mathrm{Na}$ Salvador oitocentista havia uma imbricada teia que ligava as diversas famílias de comerciantes mediante laços de amizade, parentesco e consanguinidade. Estar inserido nessas redes era fundamental para ascender no comércio e conseguir crédito. O que mulheres como a viúva Boucher e a viúva Aschlimann estavam fazendo, nada mais era do que prestar auxílio necessário para que seus familiares ou conhecidos prosperassem financeiramente e, não menos importante, elas também lucravam com isso. Essa era uma prática conhecida e frequentemente utilizada por seus pares do sexo oposto, sobretudo os comerciantes portugueses.

\section{Conclusão}

MAIS IMPORTANTE do que eventuais respostas e certezas, as discussões, impressões iniciais e as muitas dúvidas contidas neste breve artigo têm por objetivo favorecer uma reflexão mais profunda sobre o lugar das mulheres no comércio da Salvador oitocentista e de outras cidades mercantis do Brasil. Se as mulheres raramente atuavam no comércio na condição de trabalhadoras, não menos importante é perceber e tentar entender sua presença enquanto comerciante, sobretudo sua relativa preponderância numérica na capital da Bahia, se comparada com as outras capitais.

É notório que as práticas sociais, os códigos morais e os empecilhos jurídicos de fato criaram um ambiente hostil para a plena atuação das mulheres no comércio da cidade. Entretanto, nos exemplos discutidos ao longo do texto, percebe-se que nem todas essas mulheres decidiram manter-se no lugar social que Ihes foi reservado. No caso das mulheres

47 JUCEB. Contratos... n. 696, 1886. 
das classes trabalhadoras, a necessidade e a luta diária pela sobrevivência lhes obrigava a ganhar o pão de cada dia perambulando e vendendo suas mercadorias pelas ruas da cidade. Por conseguinte, os poucos exemplos de mulheres mais abonadas que decidiram atuar diretamente no comércio formal, quer com bens herdados ou próprios, são a prova de que existem aspectos desse universo ainda pouco explorados e que precisam ser melhor iluminados em pesquisas futuras.

Recebido em: 01/07/2020

Aprovado em: 05/03/2021 